\title{
Prevalence of obesity and its risk factors among Pre-University college adolescents of Belgaum city, karnataka.
}

\author{
Bijendra Banjade ${ }^{1}$, Vijaya A. Naik ${ }^{2}$, Ashwini Narasannavar ${ }^{3}$ \\ ${ }^{I}$ P.G student, M.P.H, Department of public Health, J.N. Medical College, KLE University, India. \\ ${ }^{2}$ Professor, MD, DPH, Head of Department of Public Health, J. N. Medical College, KLE University, India. \\ ${ }^{3}$ Lecturer, BDS,MPH, Department of public Health, J.N. Medical College, KLE University, India
}

\begin{abstract}
Background and Objectives: Obesity, a key risk factor for the chronic and non-communicable disease, has become a serious public health concern in both developed and developing countries. Overweight/obesity is the underlying cause of death for 2.8 million people each year. It is the fifth leading cause of risk for death. The objectives of study are to know the prevalence of obesity and factors associated with Obesity. Methodology: This cross-sectional study was conducted in the two Pre-University colleges with a sample of 330 adolescents of Belgaum city, Karnataka. Pre-designed and pre-tested questionnaire was used to elicit the required information. Height and weight was measured and Body Mass Index was calculated. Results: The prevalence of overweight and obesity was observed to be $9.1 \%$ and $5.1 \%$ respectively. Out of 330 study participants $53.9 \%$ were girls and rest were boys. Overweight/obesity was significantly associated with family history of DM, HTN and overweight/obesity, diet habit, habit of taking junk foods, doing one or the other activity while eating, not doing regular physical exercise and not participating in outdoor games. Conclusion: Adopting the healthy lifestyles, food habits and regular physical exercise can reduce the risk of becoming overweight and obese. There is need to educate the school children regarding nutrition and physical activity to promote their health.
\end{abstract}

Key words: Adolescence, Body Mass Index (BMI), Obesity, Overweight.

\section{Introduction}

In ancient days, weight gain and fat storage were viewed as a sign of health and prosperity. Today, however, as a standard of living continues to rise, weight gain and obesity is posing a growing threat to health in all countries over the world ${ }^{(1)}$.

Non-Communicable Diseases are the leading cause of death in the world and are responsible for $63 \%$ of the 57 million deaths that occurred in 2008. Globally, the leading risk factors for mortality are raised blood pressure (responsible for $13 \%$ of deaths globally), followed by tobacco use (9\%), raised blood glucose $(6 \%)$, physical inactivity $(6 \%)$, and also overweight and obesity $(5 \%)^{(2)}$.

Obesity, a key risk factor for the chronic and non-communicable disease ${ }^{(3)}$, has become a serious public health concern in both developed and developing countries ${ }^{(4)}$. Worldwide, the prevalence of chronic, non communicable diseases is increasing at an alarming rate. More than 1.1 billion adults are overweight in the world today. Among them 312 million are obese and nearly 115 million children worldwide are overweight or obese according to International Obesity Task force (IOTF) ${ }^{(5)}$. Overweight/obesity is the underlying cause of death for 2.8 million people each year ${ }^{(6)}$. It is the fifth leading cause of risk for death ${ }^{(7)}$. More than 100 million individuals are obese in India. India is in midst of an obesity epidemic, which has serious health ramifications ${ }^{(8)}$.The result of various studies among adolescents from various parts of Punjab, Maharashtra, Delhi and southIndia reveal that the prevalence of overweight and obesity is $11 \%-29 \%{ }^{(9)}$. Due to variation in definitions and non- availability of reliable data, it has been extremely difficult to assess magnitude of the problem and comparison of its prevalence in different countries ${ }^{(10)}$.

Adolescent constitute 18-25\% of the population of SEAR, India accounts for one fifth of the total population. This age group is significant human resources. Particularly in the urban areas, adolescent obesity is emerging as a major health problem as a result of change in life style, due to increased purchasing power, increased in inactivity, dietary and cultural transition ${ }^{(11)}$.Identification of risk factor is an important step towards planning the strategy for effective intervention. This study will enable to identify the magnitude of obesity and overweight among the college going adolescents and their risk factor which will eventually help to prevent the problem of obesity in the community

\section{Material and methods}

A cross-sectional study was conducted in the two pre-university colleges of Belgaum city, Karnataka from January 2013 to September 2013. Adolescents (10-19) years who gave the assent were included in the 
study. Adolescents having the chronic diseases and who were on the medication to reduce the weight were excluded from the study.

As per the published article, the sample size was calculated by taking prevalence(p) of $29 \%{ }^{(9)}$ and allowable error (d) $5 \%$ by using formula $\mathrm{N}=4 \mathrm{pq} / \mathrm{d}^{2}(\mathrm{q}=1-\mathrm{p})$ the sample size was calculated to be 329 and rounded of to 330 .

The Pre-University Colleges (PUC) colleges in Belgaum city were clustered in the North and South zones. Two PU Colleges were selected by Simple Random Sampling (Lottery Method); one from each zone. The selected two PUC were G.S.S. P.U. College and Jagadish A.Savadatti P.U.College with students of 1611 and 480 respectively. Secondly, Proportionate Systematic random sampling was applied to select the sample of 254 and 76 from the G.S.S P.U. College and Jagadish A.Savadatti P.U. College respectively to obtain desired sample of 330 .

Pre designed and pre tested questionnaire were used to collect the information on socio-demographic status, physical activities, dietary habits, life styles and anthropometric measurements. Standard Weighing machine and measurement tape were used to measure weight and height respectively.

The weighing scale was kept in the horizontal surface and participants were made to stand in the centre of the scale in erect position; without shoes and heavy clothing. The weight was measured in the unit " $\mathrm{Kg}$ " with the nearest of $0.1 \mathrm{~kg}$. The weighing machine was periodically checked to ensure the quality. Height was measured with a measuring tape; marking were done on the wall. The subject was made to stand in erect position, without footwear with feet together and head touching the wall and eye looking straight. The height was measure in the unit "cm" with nearest to $0.1 \mathrm{~cm}$.

Based on Centers for Disease Control and Prevention (CDC)-2000 growth charts for children and adolescents aged 2-20 years i.e. BMI for age and sex percentile growth curves adolescent with a BMI-for-age between $85^{\text {th }}$ to $95^{\text {th }}$ percentiles were considered "overweight" and above $95^{\text {th }}$ percentile as "Obesity" and $<5^{\text {th }}$ percentile as "Underweight"

Ethical clearance was obtained from Institutional Ethics Committee (IEC) of KLEU, J.N.M.C. Participants were fully informed and written assent was taken. Complete confidentiality of the participant's was maintained. Appropriate code was given for each participant.

Data entry and analysis was made by using Statistical Package for Social Science (SPSS) software (Version 20.0). Mean, proportion and percentage were calculated. Chi square test was applied for establishing association with $\mathrm{P}$ value $<0.05$.

\section{Results}

In this study $152(46.1 \%)$ were boys and $178(53.9 \%)$ were girls with a mean age of 16.9 years. Among them majority belonged to age 17 years $(61.5 \%$, Male $=49.3 \%$ and Female $=50.7 \%)$. Most of the people $(79.4 \%)$ were Hindus followed by Muslims (11.2\%), Jain (7.9\%) and Christians (1.5\%). Almost $67.6 \%$ of the participants belonged to nuclear family, $29.4 \%$ belonged to joint family and $3 \%$ belonged to extended family. According to modified B.G. Prasad classification $34.8 \%$ participants belonged to class II, followed by class III (24.5\%), class I (19.7\%), Class IV (16.4\%) and Class V (4.5\%).

The prevalence of overweight and obesity in the present study was $9.1 \%(9.2 \%$ among male and $9 \%$ among female) and $5.1 \%$ ( $5.3 \%$ among male and 5.1\% among female) respectively. The prevalence of underweight was $18.5 \%$ and $67.3 \%$ belonged to normal according to CDC classification of age for weight (Fig. no.1).

As per the age group, overweight/obesity was present in $12(17.1 \%)$ participants in $15-16$ years age group and $35(13.5 \%)$ participants in 17-18 years age group. Although, the prevalence of Overweight/obesity was higher in 15-16 years age group the difference was not statistically significant $\left(\chi^{2}=3.146, \mathrm{df}=2, \mathrm{p}=0.207\right)$.

In the present study the prevalence of overweight/obesity among adolescents of socioeconomic status classes as high, middle and low was found to be $32(17.8 \%), 8(9.9 \%)$ and $7(10.1 \%)$ respectively. The difference of Overweight/obesity was not statistically significant $\left(\chi^{2}=7.129, \mathrm{df}=4, \mathrm{p}=0.129\right)$ but highest prevalence was noted in high SES (class I and II).

Among the family of adolescents with a history of Diabetes Mellitus (DM), Hypertension and Overweight/obesity was found to be significantly associated (Table no. 1). 


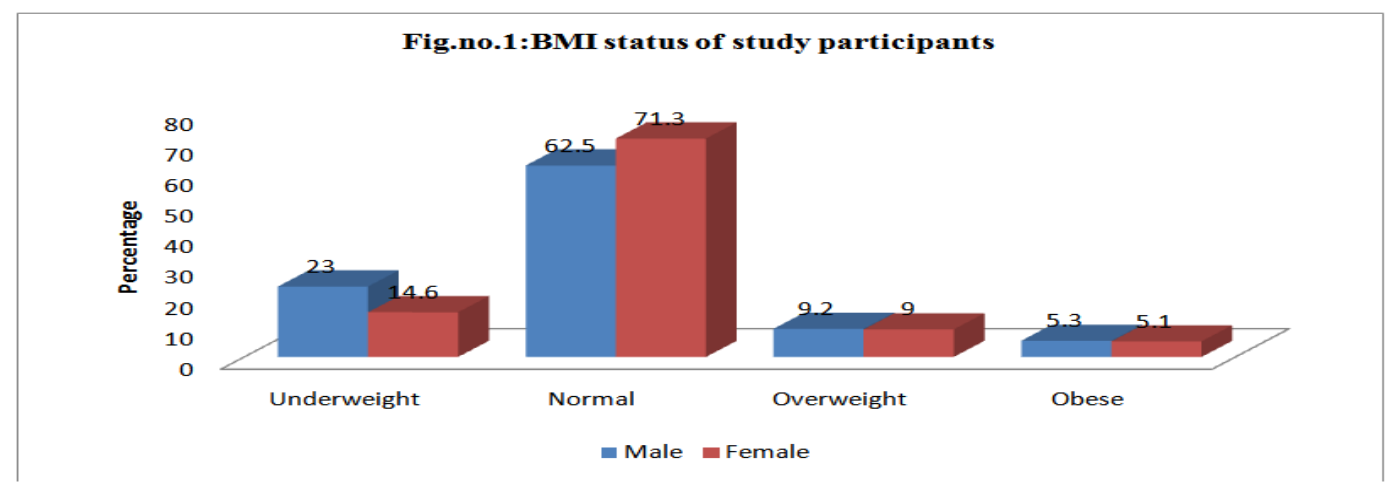

Table no 1: Association of family history of DM, HTN and Overweight/obesity with BMI

\begin{tabular}{|c|c|c|c|c|c|}
\hline \multirow{2}{*}{\multicolumn{2}{|c|}{ Family history }} & Underweight & Normal & $\begin{array}{l}\text { Overweight/Obe } \\
\text { se }\end{array}$ & Total \\
\hline & & No. $(\%)$ & No. (\%) & No $(\%)$ & No. $(\%)$ \\
\hline \multirow{3}{*}{ DM } & Yes & $8(11.9)$ & $37(55.2)$ & $22(32.8)$ & $67(20.3)$ \\
\hline & No & 53(20.2) & $185(70.3)$ & $25(9.5)$ & $\begin{array}{c}263(79.7 \\
)\end{array}$ \\
\hline & Total & $61(18.5)$ & $222(67.3)$ & $47(14.2)$ & $330(100)$ \\
\hline \multicolumn{6}{|c|}{$\chi^{2}=24.169, \mathrm{df}=2, \mathrm{p}<0.001$} \\
\hline \multirow{3}{*}{ HTN } & Yes & $10(15.4)$ & $38(58.5)$ & $17(26.2)$ & $65(19.7)$ \\
\hline & No & $51(19.2)$ & $184(69.4)$ & $30(11.3)$ & $\begin{array}{c}265(80.3 \\
) \\
\end{array}$ \\
\hline & Total & $61(18.5)$ & $222(67.3)$ & $47(14.2)$ & $330(100)$ \\
\hline & & & & \multicolumn{2}{|c|}{$\chi^{2}=9.419, \mathrm{df}=2, \mathrm{p}=0.009$} \\
\hline \multirow[t]{3}{*}{$\begin{array}{l}\text { Over-weight/ } \\
\text { Obesity }\end{array}$} & Yes & $26(17.2)$ & $79(52.3)$ & $46(30.5)$ & $\begin{array}{c}151(45.8 \\
)\end{array}$ \\
\hline & No & $35(19.6)$ & 143(79.9) & $1(0.6)$ & $\begin{array}{c}173(54.2 \\
) \\
\end{array}$ \\
\hline & Total & $61(18.5)$ & $222(67.3)$ & $47(14.2)$ & $330(100)$ \\
\hline
\end{tabular}

Diet habit (consuming non-vegetarian diet), consuming junk foods, Doing one or the other activity while eating, playing outdoor games and doing physical exercise was significantly associated with Overweight/obesity while playing indoor games has no effect on overweight/obesity (Table no.2)

Table no. 2: Association of Variables with Overweight/obesity

\begin{tabular}{|c|c|c|c|c|c|}
\hline \multicolumn{2}{|c|}{ Variables } & \multirow{2}{*}{$\begin{array}{c}\text { Under-weight } \\
\text { No (\%) } \\
\end{array}$} & \multirow{2}{*}{\begin{tabular}{|l|} 
Normal \\
No (\%) \\
\end{tabular}} & \multirow{2}{*}{$\begin{array}{c}\begin{array}{c}\text { Overweight/Ob } \\
\text { ese }\end{array} \\
\text { No }(\%) \\
\end{array}$} & \multirow{2}{*}{$\begin{array}{c}\text { Total } \\
\text { No (\%) } \\
\end{array}$} \\
\hline & & & & & \\
\hline \multirow[t]{3}{*}{ Diets } & Vegetarian & $25(17.7)$ & $106(72.2)$ & $10(7.1)$ & 141(42.7) \\
\hline & Non-Vegetarian & $36(19)$ & $116(61.4)$ & $37(19.6)$ & $189(57.3)$ \\
\hline & & & & \multicolumn{2}{|c|}{$\chi^{2}=11.20, \mathrm{df}=2, \mathrm{p}=0.004^{*}$} \\
\hline \multirow{3}{*}{$\begin{array}{l}\text { Junk } \\
\text { foods }\end{array}$} & Yes & $37(16.1)$ & $150(65.2)$ & $43(18.7)$ & $230(69.7)$ \\
\hline & No & $24(24)$ & $72(72)$ & $4(4)$ & $100(30.3)$ \\
\hline & & & & \multicolumn{2}{|c|}{$\chi^{2}=13.406, \mathrm{df}=2, \mathrm{p}<0.001$} \\
\hline \multirow{3}{*}{$\begin{array}{l}\text { Activity } \\
\text { while } \\
\text { eating }\end{array}$} & $\begin{array}{l}\text { Doing on or other } \\
\text { activity }\end{array}$ & $47(19.1)$ & $157(63.8)$ & $42(17.1)$ & $246(74.5)$ \\
\hline & Doing nothing & $14(16.7)$ & $65(77.4)$ & $5(6)$ & $84(25.5)$ \\
\hline & & & & \multicolumn{2}{|c|}{$\chi^{2}=7.350, \mathrm{df}=2, \mathrm{p}=0.025$} \\
\hline \multirow{3}{*}{$\begin{array}{l}\text { Indoor } \\
\text { games }\end{array}$} & Yes & $36(17.2)$ & 145(69.4) & $28(13.4)$ & $209(63.3)$ \\
\hline & No & $25(20.7)$ & $77(63.6)$ & $19(15.7)$ & $121(36.7)$ \\
\hline & & & & \multicolumn{2}{|c|}{$\chi^{2}=1.151, \mathrm{df}=2, \mathrm{p}=0.562$} \\
\hline \multirow{3}{*}{$\begin{array}{l}\text { Outdoor } \\
\text { games }\end{array}$} & Yes & $40(21.9)$ & $134(73.2)$ & $9(4.9)$ & $183(55.5)$ \\
\hline & No & $21(14.3)$ & $88(59.9)$ & $38(25.9)$ & $147(44.5)$ \\
\hline & & & & \multicolumn{2}{|c|}{$\chi^{2}=29.770, \mathrm{df}=2, \mathrm{p}<0.001^{*}$} \\
\hline \multirow{3}{*}{$\begin{array}{l}\text { Physical } \\
\text { exercise }\end{array}$} & Yes & $30(17.6)$ & 132(77.6) & $8(4.7)$ & $170(51.5)$ \\
\hline & No & $31(19.4)$ & $90(56.2)$ & $39(24.4)$ & $160(48.5)$ \\
\hline & & & & \multicolumn{2}{|c|}{$\chi^{2}=28.132, \mathrm{df}=2, \mathrm{p}<0.001^{*}$} \\
\hline
\end{tabular}




\section{Discussion}

Overweight and obesity is becoming an increasingly important public health problem. The prevalence of overweight and obesity was $9.1 \%$ and $4.1 \%$ respectively in our study which is similar to the study conducted in city of Manglore, Karnakata ${ }^{(23)}$. Whereas, the studies conducted in Gujarat, Punjab, Jaipur, Chennai revealed that the prevalence of overweight was as high as $(10-15 \%)$ and obesity $(5-11 \%)^{(11,17,24,26,27)}$. This difference could be due to the fact that study participants belonged to high socio-economic class with an increased purchasing power, high standard of living and change in dietary pattern and lifestyles. Compared to our results the prevalence of overweight and obesity has been as high as $12.44 \%$ and $4.10 \%$ in Hong kong ${ }^{(16)}$ whereas prevalence was also high in study done at Iran ${ }^{(10)}$ but low in Vietnam ${ }^{(13)}$.

The prevalence of overweight was $7.2 \%$ and $8.75 \%$ according the study conducted in Hyderabad ${ }^{(9)}$ and Mysore ${ }^{(20)}$ which is lower when compared with our prevalence. Study conducted in Dakshina Kannada (DK) ${ }^{(19)}$, Nagpur ${ }^{(25)}$, and Wardha city ${ }^{(28)}$ reported the prevalence of overweight and obesity to be low (4-7\%), this result may be due to the study participants from both urban/rural area and of low SES.

The prevalence of overweight and obesity was found to be higher among boys (14.5\%) as compared to girls. This could be due to cultural preferences as giving more advantage to boys in terms of diet and not involving boys in household activities. Our findings are consistent with studies conducted in Gujarat, Punjab, Dakshina Kannada, and Delhi ${ }^{(4,11,17-19,21)}$ and other countries like Iran, Vitenam and Hongkong ${ }^{(10,13,16)}$. But the girls were more overweight and obese than boys in studies conducted in Hyderabad, Gujarat, Punjab, Jaipur, Chennai, Ghanna and Uganda ${ }^{(9,14,22,24,26,27)}$.

In our study, prevalence of overweight and obesity was more in 15-16 years age group. This was comparable to the findings of studies conducted in Punjab and $\mathrm{DK}{ }^{(9,19)}$. Whereas in the study conducted in Gujarat prevalence of overweight and obesity was more in age group 16-17 years ${ }^{(11)}$.

In the present study, among 330 study participants of age group 15-18 years, $46.1 \%$ were boys and $53.9 \%$ were girls with a male to female sex ratio of $0.85: 1$. The study finding was similar to studies conducted in Hyderabad, Nigeria, Hong kong, Punjab and Wardha city ${ }^{(9,15-17,28)}$ whereas in the studies conducted in Gujarat, Punjab, Nagpur and Jaipur boys were more as compared to girls ${ }^{(4,11,21-25)}$.

In our study, majority (79.4\%) were Hindus. Most of the participants belonged to class II and III socioeconomic status. A similar study conducted in Gujarat showed that majority of adolescents were Hindus and belonged to class II and III SES and this study were very much comparable to our study ${ }^{(11)}$.

Prevalence of overweight and obesity was noted to be high among adolescents of high SES in our study. This association may be due to adolescents have more access to TV and computer, sedentary life style and less physical activity. The high prevalence also noted among high SES in the studies conducted in Gujarat, Hyderabad, Punjab, South Karnataka and Chennai ${ }^{(4,9,11,12,17,23,27)}$.

Our study revealed that family history of DM, HTN and Overweight/obesity was significantly associated with prevalence of overweight/obesity $(\mathrm{P}<0.001)$. This was comparable to the study conducted in Delhi ${ }^{(4)}$.

The prevalence of overweight and obesity was found higher among adolescents who were consuming non-vegeterian diet $(\mathrm{p}=0.004)$. On the contrary, studies conducted in Delhi and Wardha city revealed there was no effect of diet as a risk factor of overweight/obesity ${ }^{(4,27)}$. Consumption of junk foods was significantly associated with overweight/obesity $(\mathrm{p}<0.001)$ in our study. Similar results were observed in studies conducted in Gujarat, Hyderabad, DK, Jaipur ${ }^{(4,9,11,19,21, \text { and 26). }}$

Analysis of association of BMI with participation in outdoor games and doing physical exercise among adolescents revealed that participation in outdoor games and doing physical exercise was significantly associated with prevalence of overweight and obesity. But these risk factors were not found to be associated with time spent on such activities. The results were consistent with the studies conducted at Gujarat, Hyderabad, Delhi, DK and Udupi, Mysore and Jaipur ${ }^{(4,9,11,12,19,20,26)}$. However the study conducted at Delhi revealed no significant association of BMI with physical exercise and sports ${ }^{(21)}$. The study conducted in Wardha city, revealed that time spent $\geq 30$ minutes in outdoor games results in less prevalence of overweight and obesity and it was found to be significant ${ }^{(28)}$.

\section{Acknowledgement}

We are thankful to Mr. M.D Mallapur, Statistician, Department of Community Medicine, JN Medical College and also to the principal of P.U Colleges and both teaching and non-teaching staffs and study subjects for their cooperation.

Conflict of Interest: NIL

Funding: No source of funding 


\section{References}

[1]. WHO. Obesity: Preventing and managing global epidemics. Geneva, Switzerland: WHO technical report series 894 ; 1999. URL:http://whqlibdoc.who.int/trs/WHO TRS 894.pdf

[2]. WHO. Non communicable diseases country profiles. Geneva, Switzerland: WHO press; 2011. URL:http://www.who.int/nmh/publications/ncd_profiles_report.pdf

[3]. Park K. Text book of preventive and social medicine. $21^{\text {st }}$ ed. Jabalpur: 2011. Chapter 6, obesity; p. 366-70.

[4]. Goyal RK, Shah VN, Saboo BD, Phatak SR, Shah NN, Gohel MC, et al. Prevalence of Overweight and Obesity in Indian Adolescent School Going Children: Its Relationship with Socioeconomic Status and Associated Lifestyle Factors. JAPI 2010; 58:151-58.

[5]. Parvez H, Bisher K, Nahas ME. Obesity and Diabetes in developing world-A growing challenges. N. Engl J Med. 2007; 356(3):213-15.

[6]. WHO. World health statistics. Geneva, Switzerland: WHO http://www.who.int/gho/publications/world_health_statistics/EN_WHS 2012_full.pdf.

[7]. WHO. Population based prevention strategies for childhood obesity. Geneva, Switzerland: Report of WHO forum and technical meeting; 2009.URL: http://www.who.int/dietphysicalactivity/childhood/child-obesity-eng.pdf

[8]. Bhalwar R. Text book of Public Health and Community Medicine. $1^{\text {st }}$ ed. Pune: Department of Community Medicine, Armed Forces Medical College; 2009. Chapter 210, Nutrition and disease of lifestyle; p.1199-1203.

[9]. Laxmaiah A, Nagalla B, Vijayraghavan K, Nair M. Factors Affecting Prevalence of Overweight Among 12- to 17-year-old Urban Adolescents in Hyderabad, India. North American Association for the Study of Obesity (NAASO) 2007; 15(6):1384-90.

[10]. Mirzasadeh A, Sadeghirad B, Haghdoost AA, Bahrein F, Kermani MR. The prevalence of obesity in Iran in recent decades; a systematic review and meta-analysis study. Iranian J Publ Health 2009; 38(3):1-11.

[11]. Brahmbhatt KR, Umesh ON. Obesity among adolescent of Ahmadabad city, Gujrat, India-a community based cross sectional study. Int. J Biol Med Res. 2012; 3(2);1554-57

[12]. Kaur S, Sachdev HPS, Dwivedi SN, Lakshmy R, Kapil U. Prevalence of overweight and obesity amongst school children in Delhi, India. Asia Pac J Clin Nutr 2008; 17(4):592-96.

[13]. Tang HK, Dibley MJ, Sibbritt D, Tran HMT. Gender and socio-economic differences in BMI of secondary high school students in Ho Chi Minh City Gender and socio-economic differences in BMI of secondary high school students in Ho Chi Minh City: Asia Pac J Clin Nutr 2007; 16 (1):74-83.

[14]. Peltzer K, Pengped S. Overweight and Obesity and Associated Factors among School-Aged Adolescents in Ghana and Uganda. Int. J. Environ. Res. Public Health 2011; 8: 3859-70.

[15]. Akinpelu AO, Oyewole OO, Oritogun KS. Overweight and Obesity: Does It Occur In Nigerian Adolescents in an Urban Community?. International journal of Biomedical and Health Sciences, 2008 March 31; 4(1):11-17.

[16]. Ko GTC, Ozaki R, Wong GWK, Kong APS, So WY, Tong CY, et.al. The problem of obesity among adolescents in Hong Kong: a comparison using various diagnostic criteria. BMC Pediatrics 2008 March 4; 8(10).

[17]. Chhatwal J, Verma M, Riar SK. Obesity among pre-adolescent and adolescents of a developing country (India). Asia Pac J Clin Nutr 2004; 13 (3):231-35

[18]. Aggrawal T, Bhattia RC, Singh D, Sobti PC. Prevalence of Obesity and Overweight in Affluent Adolescents from Ludhiana, Punjab. Journal of Indian Pediatrics 2008 June 17; 45: 500-02.

[19]. Keerthan Kumar M., Prashanth K., Baby KE, Rao KR, Kumarkrishna B, Hegde K, et.al . Prevalence of obesity among high school children in dakshina Kannada and Udupi districts. NUJHS 2011 Dec.;1(4):16-20.

[20]. Saraswathi YS, Najafi M, Gangadhar MR, Malini SS. Prevalence of Childhood Obesity in School Children from Rural and Urban Areas in Mysore, Karnataka, India. J Life Sci, 2011; 3(1): 51-55.

[21]. Singh AK, Maheshwari A, Sharma N, Anand K. Lifestyle Associated Risk Factors in Adolescents. Indian Journal of Pediatrics 2006 Oct.; 73(10):901-06.

[22]. Alok P, Malay P, Divyeshkumar V. Prevalence of overweight and obesity in adolescents of urban \& rural area of surat, Gujarat. National Journal of Medical Research 2012 July-Sept.; 2(3):325-29.

[23]. Kotian MS, S. Ganesh Kumar, Kotian SS. Prevalence and determinants of overweight and obesity among adolescent school children of South Karnataka, India. Indian journal of community Medicine 2010; 35 (1): 176-78.

[24]. Sidhu S, Marwah G, Prabhjot. Prevalence of Overweight and Obesity among the Affluent Adolescent School Children of Amritsar, Punjab. Coll. Antropol. 29 2005; 1: 53-55.

[25]. Deoke A, Hajare S, Saoji A. Prevalence of Overweight in High School Students with Special Reference to Cardiovascular Efficiency. Global Journal of Health Science 2012; 4(2):147-52.

[26]. Bansal AK, Monohar R, Yadav R, Sharma D, Yadav N, Lohani H. Prevalence of obesity and its lifestyle risk factors in school age children in Jaipur. IJRRMS 2013; 3(2):16-19.

[27]. Thakur S, Viswanathan V. Impact of socioeconomic status on prevalence of overweight and obesity among children and adolescents in Urban India. The open obesity journal 2009;1: 9-14

[28]. Bharati DR, Deshmukh PR., Garg BS. Correlates of overweight/obesity among school going children of Wardha city, Central India. Indian J Med Res 1272008 June: 539-43 